\title{
Water activity of the bee fungal pathogen Ascosphaera apis in relation to colony conditions
}

\author{
Jay A. Yoder ${ }^{1}$, Blake W. NeLson ${ }^{1}$, Leighanne R. MAIN ${ }^{1}$, Andre L. LoREnz ${ }^{1}$, \\ Andrew J. JAJACK ${ }^{2}$, Katherine A. AronsteIN ${ }^{3}$ \\ ${ }^{1}$ Department of Biology, Wittenberg University, Springfield, OH 45501, USA \\ ${ }^{2}$ Department of Biomedical, Chemical \& Environmental Engineering, University of Cincinnati, Cincinnati, OH 45267, \\ USA \\ ${ }^{3}$ Honey Bee Breeding, Genetics and Physiology Research Unit, United States Department of Agriculture, Agricultural \\ Research Service, Baton Rouge, LA 70820, USA
}

Received 9 October 2015 - Revised 8 April 2016 - Accepted 6 July 2016

\begin{abstract}
We report factors that are limiting for Ascosphaera apis growth: water activity $\left(\mathrm{a}_{\mathrm{w}}\right)$ and temperature. Features of A. apis were a high water activity, $0.85-0.90 \mathrm{a}_{\mathrm{w}}$ at $25 / 30{ }^{\circ} \mathrm{C}$ and $0.90-0.95 \mathrm{a}_{\mathrm{w}}$ at $35^{\circ} \mathrm{C}$. A minimum water activity of $0.95 \mathrm{a}_{\mathrm{w}}$ was required to produce spores. None of these characteristics changed from cycling or descending/ascending between low and high water activity media. Growth rates varied between isolates. This new study provides the biological data for monitoring and early prediction of disease outbreaks. Beekeepers should note that A. apis has a high water activity for spore production. Healthy bees that keep the internal brood area hot and dry can critically limit incidence of infection and transmission via spores.
\end{abstract}

\section{chalkbrood / bee colony / mycosis / relative humidity / water balance / microcosm}

\section{INTRODUCTION}

Excess moisture, dampness, and high relative humidity have been noted by beekeepers to be a problem within managed honey bee (Apis mellifera ) colonies by causing chalkbrood disease that kills bee larvae. This disease is caused by the fungus Ascosphaera apis (Aronstein and Cabanillas 2012). Symptoms of chalkbrood are the grayish-white to black, hardened remains of bee larvae in cells and around bottom boards due to detachment of mummified remains or by cleaning by hygienic bees. Weak or compromised bee colonies from stress of mites, bacterial and

Corresponding author: A. Jajack, jajackaj@mail.uc.edu

Manuscript editor: Yves Le Conte

Mention of a propriety product does not constitute an endorsement or use of the product by the U.S.D.A. viral infections, malnutrition, and bees that are not able to ventilate the colony properly are vulnerable to chalkbrood (Aronstein and Cabanillas 2012). Low temperature and high relative humidity perpetuate the disease (Flores et al. 1996). In the USA, the disease often appears in late springearly summer during the buildup of the brood. During this time, the brood population is larger than the population of workers. The shift in population puts stress on regulation of temperature and relative humidity within the colony environment (Koenig et al. 1987).

Transmission of chalkbrood and infection has to do with spores (=ascospores) (Evison 2015). As a heterothallic fungus, heavy spore production is a feature of A. apis (Maassen ex Claussen) Olive et Spiltoir, teleomorph (listed as ARSEF 7405 and ARSEF 7406 by the USDA-ARS Collection of Entomopathogenic Fungal Cultures, Ithaca, New York). Spores become incorporated into bee bread that is fed to larval bees that become infected, 
mummifying the larva (Aronstein and Cabanillas 2012). Furthermore, A. apis can be introduced into a colony by re-using frames and hive construction materials from old diseased colonies. The substrate for A. apis is bee larvae and germination of $A$. apis spores occurs in the larval midgut (Aronstein and Cabanillas 2012). Fungal growth and sexual reproduction on larval cadavers and chalkbrood mummies are affected by the colony environment. High relative humidity will support production of ascospores.

The moisture content of a material that is suitable for fungal growth is described by water activity $\left(\mathrm{a}_{\mathrm{w}}\right): \mathrm{a}_{\mathrm{w}}=p / p_{0}$, where $p$ is the water vapor pressure of a solution and $p_{0}$ is the water vapor pressure of pure water (Carlile et al. 2001; Liu et al. 2012). Water activity $\left(a_{w}\right)$ is related to water potential $(\Psi)$ that reflects water movement from substrate into the fungus. Pure water $=1.00 \mathrm{a}_{\mathrm{w}}$ $(\Psi=0 \mathrm{MPa})$. "Wet" surfaces are $\geq 0.90 \mathrm{a}_{\mathrm{w}}$ $(\Psi \geq-14 \mathrm{MPa})$, and "damp" surfaces are 0.65$0.85 \mathrm{a}_{\mathrm{w}}$ ( $\Psi=-60$ to $-22 \mathrm{MPa}$ ) (Liu et al. 2012). In the absence of an adequate water, spores do not germinate, no hyphae grow, and no spores are produced that lead to additional infections (Carlile et al. 2001). Relative humidity of $87 \%$ $\mathrm{RH}$ and temperature of $30^{\circ} \mathrm{C}$ yield a high proportion of mummies when bee larvae are artificially infected (Flores et al. 1996). Spores of A. apis fail to germinate below $80 \%$ RH (Liang et al. 2000). Neither the water activity of $A$. apis that lead to spore production nor its connection to temperatures that are in a bee colony have been studied. Experimentation in this area could explain how this pathogen works relative to the colony environment supporting secondary spore production from larval cadavers.

Water activity-temperature relationships are examined in this paper, with the goal of exploring survival elements of $A$. apis in relation to the minimal water activity for growth and how this fungus responds to changing environmental conditions within the bee colony. Some isolates of A. apis are more infective to larvae than other isolates (Aronstein and Cabanillas 2012; Evison 2015). Some isolates of $A$. apis are genetically distinct; i.e., the LBR and JBR isolates from Louisiana in this study. Four different isolates of
A. apis were examined in this study. The purpose of examining these isolates is to determine whether different isolates have different water activities. We are testing the hypothesis that water activity may affect the ability of $A$. apis to grow and produce spores. In particular, different isolates may have different water activities that could account for differences in virulence as related to production of ascospores.

\section{MATERIALS AND METHODS}

\subsection{Fungi and experimental design}

The origin of isolates of $A$. apis was from chalkbrood mummies from infected colonies so that results reflect what would be occurring in the bee colony. Isolates contain a mixture of both mating types from natural chalkbrood mummies. Purification of A. apis was done by three rounds of subculturing of hyphal tips on potato dextrose agar $(\mathrm{PDA})+0.4 \%$ yeast extract (Fisher Scientific, Pittsburgh, Pennsylvania). Culturing was done in $100 \times 15 \mathrm{~mm}$ Petri plates (Fisher), at $30 \pm 0.5^{\circ} \mathrm{C}$ and darkness. Ascospore, spore cyst characteristics, and comparison to reference isolate A. apis (ARSEF 7405; ARSEF 7406) were used for identification (Christensen and Gilliam 1983). The isolate from Arizona was designated as $\mathrm{AZ}$ and it is in storage in Springfield Ohio by J. Yoder. Three isolates came from Louisiana and are in storage in Baton Rouge, Louisiana by $\mathrm{K}$. Aronstein. One of the Louisiana isolates came from old, frozen infected larval tissue and was designated as BBR. Another isolate came from recycled comb and was designated as JBR. The third isolate also came from recycled comb and was designed as LBR. The JBR and LBR isolates are genetically distinct. The acronyms for these isolates are used in this study so that they match colony records in our storage libraries.

Experiments were conducted on potato dextrose agar $(\mathrm{PDA})+0.4 \%$ yeast extract that allowed for more precise control of water activity. Incorporating glycerol (>99.5 \%; Sigma Chemical Co., St. Louis, Missouri) into the medium (Rousseau and Donèche 2001) was used to adjust water activity $\left(\mathrm{a}_{\mathrm{w}}\right)$. Water activity was measured with a hygrometer ( $\mathrm{SD} \pm 0.005 \% \mathrm{a}_{\mathrm{w}}$; Thomas Scientific, Philadelphia, Pennsylvania). Incubation was carried out in programmable incubators (SD $< \pm 0.5^{\circ} \mathrm{C}$; Fisher). Temperatures were selected 
that have relevance to the colony environment and chalkbrood: $25^{\circ} \mathrm{C}$ (onset of chalkbrood infection, yields largest number of mummies), $30{ }^{\circ} \mathrm{C}$ ('critical temperature' for chalkbrood and measurement of infection), and $35{ }^{\circ} \mathrm{C}$ (temperature of central brood area, offset of chalkbrood infection) (Flores et al. 1996). The $35^{\circ} \mathrm{C}$ approximates the mean within the $33-36{ }^{\circ} \mathrm{C}$ temperature range for proper brood rearing that is maintained throughout the year by healthy bees (Ellis 2008).

The basic method for determination of the growth rate is as follows. Two lines were drawn on the bottom of a Petri plate that divided the plate into quadrants. Agar (adjusted to a specific $\mathrm{a}_{\mathrm{w}}$ ) was poured into the plate and allowed to solidify. A $1-\mathrm{cm}^{3}$ block of A. apis (contains both mating types, because it was isolated originally from grayish-black mummies) was taken from a 2-week established culture that we had grown in the laboratory. The block of A. apis inoculum was placed at the center of the Petri plate on the agar surface over top the intersection of the two lines that had been drawn on the bottom of the plate. The Petri plate was placed into the incubator. As the mycelium grew, the mycelium growth radiated outward from the center (from where the block of inoculum had been placed). As the mycelium spread over the agar surface from the center of the plate, the distance that the mycelium traveled was measured by tracking the advancing edge of the mycelium. So that the edge of the mycelium could be tracked in the same area, the measurements were made along the lines that had been drawn on the bottom of the plate. The measurements were spread out by $4-8-\mathrm{mm}$ increments, depending on test temperature and test water activity as the spread of the mycelium was faster under some conditions rather than at others. Growth rate was calculated from 10 measurements per line ( $n=20$ measurements/plate) made at $450 \times$ light microscopy. The experimental period for measuring growth was 1 week. The growth rate was calculated by the equation $K_{\mathrm{r}}=\left(R_{1}-R_{0}\right) /\left(t_{1}-t_{0}\right)$, where $K_{\mathrm{r}}$ is the radial growth rate, $R_{0}$ and $R_{1}$ are colony radii at the beginning of linear, $t_{0}$, and stationary, $t_{1}$, phases of growth (Baldrian and Gabriel 2002).

\subsection{Water activity experiments}

The $0.95 \mathrm{a}_{\mathrm{w}}$ was the lowest water activity where A. apis grew and produced spores. Isolates were grown for three successive generations (defined when black ascospores appeared) at the lowest $\left(0.95 \mathrm{a}_{\mathrm{w}}\right)$ and highest $\left(0.996 \mathrm{a}_{\mathrm{w}}\right)$ water activities at $30{ }^{\circ} \mathrm{C}$ for 4 weeks. The purpose of creating these $0.95 \mathrm{a}_{\mathrm{w}}$-history and $0.996 \mathrm{a}_{\mathrm{w}}$-history cultures is to find out whether we can make this fungus more wet- or dry-suited; these are standard experiments in water balance physiology experiments (Hadley 1994).

In the first experiment, growth rates were determined for $0.95 \mathrm{a}_{\mathrm{w}}$-history and $0.996 \mathrm{a}_{\mathrm{w}}$-history cultures at $0.996,0.98,0.96,0.95,0.90,0.85,0.80,0.75,0.70$, $0.65,0.60,0.55,0.50$, and $0.40 \mathrm{a}_{\mathrm{w}} \mathrm{s}$. The radial growth rate was measured at three different temperatures, 25 , 30 , and $35^{\circ} \mathrm{C}$. The slope of a regression line through the points on a plot of growth rate over water activity was expressed as $m m / h / \Delta \mathrm{a}_{\mathrm{w}}$. The slope of the regression line represents growth over the changing water activity range where growth occurred (Hadley 1994).

The purpose of second experiment was to determine whether $0.95 \mathrm{a}_{\mathrm{w}}$-history cultures of A. apis retain its growth characteristics following exposure to a higher water activity environment. Conversely, $0.996 \mathrm{a}_{\mathrm{w}}$-history cultures were examined to determine whether they retain their growth characteristics following exposure to a lower water activity environment. To do so, growth rates were determined at $30{ }^{\circ} \mathrm{C}$ for $0.996 \mathrm{a}_{\mathrm{w}}$-history cultures at $0.996,0.98,0.96,0.95,0.90,0.85,0.80$, $0.75,0.70,0.65,0.60,0.55,0.50,0.40 \mathrm{a}_{\mathrm{w}} \mathrm{s}$. This experiment was repeated using $0.95 \mathrm{a}_{\mathrm{w}}$-history cultures.

Exposure between low and high water activity extremes can also lead to becoming more dry- or wet-suited, respectively (Hadley 1994). As a third experiment, a cycling pre-conditioning was done prior to determination of growth rates at $0.996,0.98,0.96,0.95,0.90,0.85,0.80$, $0.75,0.70,0.65,0.60,0.55,0.50,0.40 \mathrm{a}_{\mathrm{w}} \mathrm{s}$. To do so, a $0.996 \mathrm{a}_{\mathrm{w}}$-history culture was grown at $0.95 \mathrm{a}_{\mathrm{w}}$ for one sporing generation, and then an inoculum-block of the mycelium was transferred back and re-grown at $0.996 \mathrm{a}_{\mathrm{w}}$ for one sporing generation. The same was done for $0.95 \mathrm{a}_{\mathrm{w}}$-history culture that was grown at $0.996 \mathrm{a}_{\mathrm{w}}$, and then transferred back on to $0.95 \mathrm{a}_{\mathrm{w}}$ media. Growth rates were expressed as $\mathrm{mm} / \mathrm{h} / \Delta \mathrm{a}_{\mathrm{w}}$ to reflect growth over the water activity range.

A gradual increase, or decrease in wetness, or dryness, has also been shown to lead to becoming more wet- or dry-suited (Hadley 1994). The fourth experiment was to determine whether $A$. apis could be made to be more dry-suited, or wet-suited, by serial exposure to a descending, or ascending, water activities. Temperature was $30{ }^{\circ} \mathrm{C}$. Thus, $0.996 \mathrm{a}_{\mathrm{w}^{-}}$and $0.95 \mathrm{a}_{\mathrm{w}}$-history cultures of $A$. apis were first plated at $0.996 \mathrm{a}_{\mathrm{w}}$. From the mycelium at $0.996 \mathrm{a}_{\mathrm{w}}$, a block of inoculum was 
taken and transferred to $0.98 \mathrm{a}_{\mathrm{w}}$ and allowed to growth. From the mycelium that grew at $0.98 \mathrm{a}_{\mathrm{w}}$, a block of inoculum was taken and transferred to $0.96 \mathrm{a}_{\mathrm{w}}$, and so on, along the water activity series. Transfers were continued in a stepwise fashion downward (ramp down) until a water activity was reached where no growth occurred. The reverse (ramp up) was done, where it was determined if $A$. apis could become more wetsuited by starting from low water activity and doing a progression upward through the water activity series.

\subsection{Sample sizes and statistics}

Each one of the four experiments that were listed above was performed on each isolate, AZ, LBR, BBR, and JBR. For each isolate, all four experiments were replicated three times. Each replicate consisted of three separate cultures of each isolate; e.g., for $\mathrm{AZ}$, there were three separate cultures that were made of the AZ isolate so that the same culture was not used for all experiments. The same was done for LBR, BBR, and JBR. There were 15 Petri plates for determination of radial growth rate in each replicate. This means that each individual reported mean radial growth rate (i.e., each point in Fig. 1) is

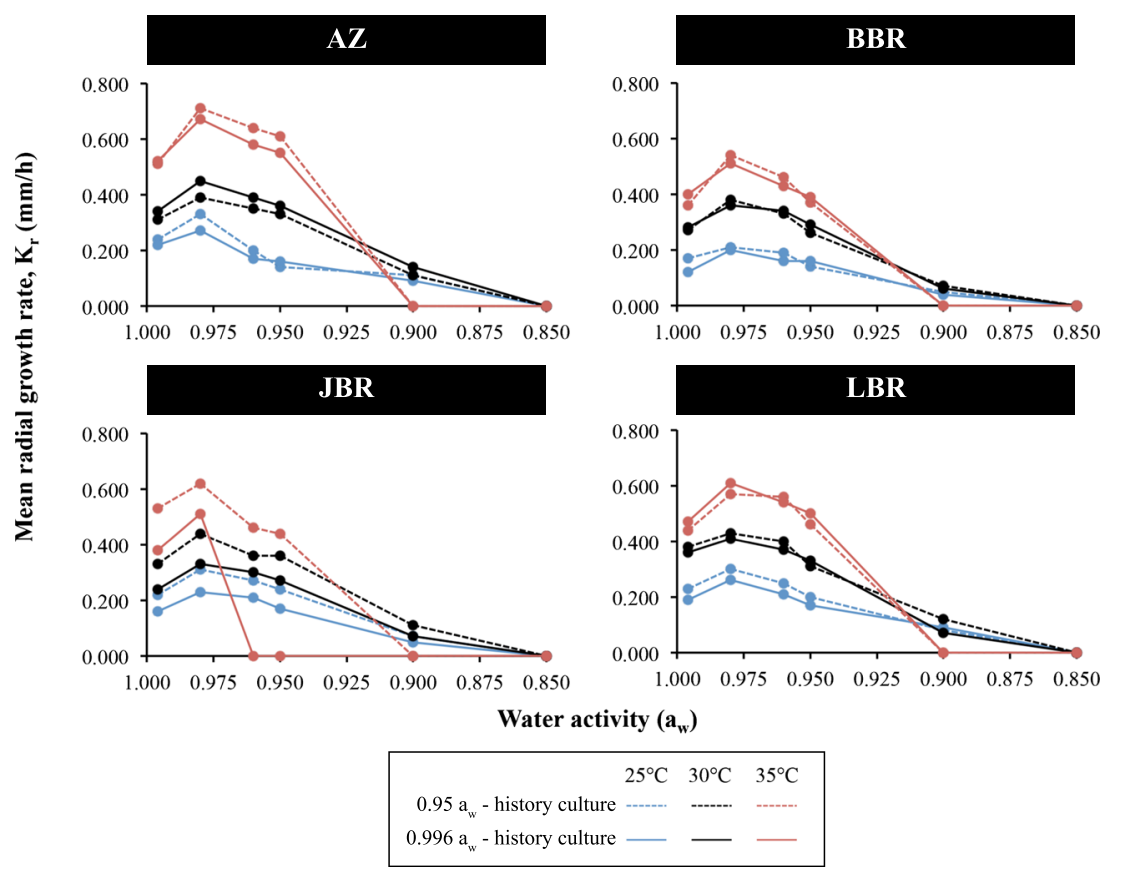

Figure 1. Water activity-temperature growth curves of Ascosphaera apis. AZ, BBR, JBR, LBR are different isolates; $a_{w}$ water activity, $K_{r}$ radial growth rate. Data are the mean $K_{\mathrm{r}} \pm \mathrm{SE} \leq 0.014$. based on a total of 900 individual measurements (i.e., 20 individual measurements/plate $\times 15$ plates/replicate $\times 3$ replicates $=900$ measurements). Data are reported as the mean $\pm \mathrm{SE}$. An analysis of variance with a logit transformation in the case of percentages (ANOVA; $P=0.05$ ) was used to compare data. Our data met the assumptions of normality and homogeneity of variances by Kolmogorov-Smirnov and Bartlett's tests before statistical analysis. If significance was found, a post-hoc analysis (Tukey's method) was used to further stratify the groups. Computer software was SPSS 14.0 for Windows (IBM, Armonk, New York), Microsoft Excel (Redmond, Washington), and Minitab (Chicago, Illinois). Regression lines were compared using Sokal and Rohlf's (1995) test for the equality of slopes. Multiple comparisons were made with each variable as the covariate.

\section{RESULTS}

\subsection{Growth curves}

A description of patterns based on Fig. 1 was that the optimum water activity for growth was $0.98 \mathrm{a}_{\mathrm{w}}$ and growth increased with increasing 
temperature. Another observable pattern was that growth occurred at $0.90 \mathrm{a}_{\mathrm{w}}$ at 25 and $30{ }^{\circ} \mathrm{C}$, but a higher water activity of $0.95 \mathrm{a}_{\mathrm{w}}$ was necessary for growth at $35^{\circ} \mathrm{C}$. There was no difference between $0.996 \mathrm{a}_{\mathrm{w}^{-}}$and $0.95 \mathrm{a}_{\mathrm{w}}$-history cultures among the different isolates, with the exception of JBR. A difference compared to other isolates was that for JBR the $0.996 \mathrm{a}_{\mathrm{w}}$-history culture required at least $0.98 \mathrm{a}_{\mathrm{w}}$ to grow at $35{ }^{\circ} \mathrm{C}$. Prior conditioning of JBR at $0.996 \mathrm{a}_{\mathrm{w}}$ resulted in suppression of growth over a broad range of water activities (Table I). Among $0.95 \mathrm{a}_{\mathrm{w}}$-history cultures, BBR consistently showed slower growth compared to other isolates $(P<0.05)$. Thus, BBR is the slower grower and JBR shows differences between $0.996 \mathrm{a}_{\mathrm{w}}$ - and $0.95 \mathrm{a}_{\mathrm{w}}$-history cultures.

\subsection{Cycling between low and high water activities}

The overall pattern was that growth at $30{ }^{\circ} \mathrm{C}$ was not altered by pre-conditioning at $0.90 \mathrm{a}_{\mathrm{w}}$ (lowest $\mathrm{a}_{\mathrm{w}}$ where growth occurred) or $0.996 \mathrm{a}_{\mathrm{w}}$ (highest $\mathrm{a}_{\mathrm{w}}$ where growth occurred), or when alternating between these water activity extremes (Table II). Except for JBR, there was no difference between $0.996 \mathrm{a}_{\mathrm{w}}$ - and $0.95 \mathrm{a}_{\mathrm{w}}$-history cultures among the different isolates. BBR was characterized by growing slower compared to the other isolates $(P<0.05)$. We conclude that high water activity of $0.996 \mathrm{a}_{\mathrm{w}}$ is suppressive toward JBR growth regardless of its prior culture history.

\subsection{Serial exposure through a water activity gradient}

In general, the mean radial growth rate was higher at $0.98 \mathrm{a}_{\mathrm{w}}$ than at other water activities and no growth occurred at or below $0.85 \mathrm{a}_{\mathrm{w}}$ that would enable us to continue further down the water activity series. Table III contains the ramp down data. No differences were noted (JBR excepted) between the $0.996 \mathrm{a}_{\mathrm{w}}-$ and $0.95 \mathrm{a}_{\mathrm{w}}$-history cultures among different isolates. When the same water activity was compared across isolates, growth rate of BBR was the lowest. None of the isolates had different growth rates when descending (ramp down), or ascending (ramp up), through the water activity series. JBR was the exception. Corresponding ramp up data for JBR (0.996 $\mathrm{a}_{\mathrm{w}}$-history culture) are the following: $0.05 \pm 0.006 \mathrm{~mm} / \mathrm{h}$ at $0.90 \mathrm{a}_{\mathrm{w}}, 0.34 \pm 0.009 \mathrm{~mm} / \mathrm{h}$ at $0.95 \mathrm{a}_{\mathrm{w}}, 0.37 \pm 0.011 \mathrm{~mm} / \mathrm{h}$ at $0.96 \mathrm{a}_{\mathrm{w}}$, $0.40 \pm 0.008 \mathrm{~mm} / \mathrm{h}$ at $0.98 \mathrm{a}_{\mathrm{w}}$, and $0.32 \pm 0.005 \mathrm{~mm} / \mathrm{h}$ at $0.996 \mathrm{a}_{\mathrm{w}}$. Corresponding ramp up data for JBR ( $0.95 \mathrm{a}_{\mathrm{w}}$-history culture) are the following: $0.12 \pm 0.007 \mathrm{~mm} / \mathrm{h}$ at $0.90 \mathrm{a}_{\mathrm{w}}$, $0.37 \pm 0.005 \mathrm{~mm} / \mathrm{h}$ at $0.95 \mathrm{a}_{\mathrm{w}}, 0.36 \pm 0.011 \mathrm{~mm} / \mathrm{h}$ at $0.96 \mathrm{a}_{\mathrm{w}}, 0.45 \pm 0.008 \mathrm{~mm} / \mathrm{h}$ at $0.98 \mathrm{a}_{\mathrm{w}}$, and $0.32 \pm 0.012 \mathrm{~mm} / \mathrm{h}$ at $0.996 \mathrm{a}_{\mathrm{w}}$. The trend for JBR is that the reduction in mean radial growth rate

Table I. Temperature effect on the growth rate of Ascosphaera apis.

$\mathrm{mm} / \mathrm{h} / \Delta \mathrm{a}_{\mathrm{w}}$ rate of growth over water activity range

\begin{tabular}{lllll}
\hline $\begin{array}{l}\text { Culture history } \\
25^{\circ} \mathrm{C}\end{array}$ & AZ & BBR & JBR & LBR \\
$0.95 \mathrm{a}_{\mathrm{w}}$ & $1.90 \pm 0.4^{\mathrm{a}}$ & $1.45 \pm 0.3^{\mathrm{a}}$ & $2.04 \pm 0.2^{\mathrm{a}}$ & $1.97 \pm 0.2^{\mathrm{a}}$ \\
$0.996 \mathrm{a}_{\mathrm{w}}$ & $1.68 \pm 0.3^{\mathrm{a}}$ & $1.23 \pm 0.2^{\mathrm{a}}$ & $1.51 \pm 0.3^{\mathrm{b}}$ & $1.60 \pm 0.3^{\mathrm{a}}$ \\
$30^{\circ} \mathrm{C}$ & & & \\
$0.95 \mathrm{a}_{\mathrm{w}}$ & $2.67 \pm 0.3^{\mathrm{b}}$ & $2.52 \pm 0.3^{\mathrm{b}}$ & $2.92 \pm 0.4^{\mathrm{c}}$ & $3.07 \pm 0.4^{\mathrm{b}}$ \\
$0.996 \mathrm{a}_{\mathrm{w}}$ & $2.94 \pm 0.2^{\mathrm{b}}$ & $2.56 \pm 0.4^{\mathrm{b}}$ & $2.23 \pm 0.2^{\mathrm{d}}$ & $3.05 \pm 0.5^{\mathrm{b}}$ \\
$35^{\circ} \mathrm{C}$ & & & \\
$0.95 \mathrm{a}_{\mathrm{w}}$ & $5.19 \pm 0.2^{\mathrm{c}}$ & $3.74 \pm 0.5^{\mathrm{c}}$ & $4.65 \pm 0.4^{\mathrm{e}}$ & $4.33 \pm 0.2^{\mathrm{c}}$ \\
$0.996 \mathrm{a}_{\mathrm{w}}$ & $4.99 \pm 0.4^{\mathrm{c}}$ & $3.78 \pm 0.4^{\mathrm{c}}$ & $2.83 \pm 0.3^{\mathrm{c}}$ & $4.55 \pm 0.3^{\mathrm{c}}$ \\
\hline
\end{tabular}

a, b, c, d, Values followed by the same superscript letter within a column are not significantly different 
Table II. Effect of cycling between low and high water activity on growth of Ascosphaera apis.

\begin{tabular}{|c|c|c|c|c|}
\hline \multirow[t]{2}{*}{ Growth history } & \multicolumn{4}{|c|}{$\mathrm{mm} / \mathrm{h} / \Delta \mathrm{a}_{\mathrm{w}}$ rate of growth over water activity range, $30{ }^{\circ} \mathrm{C}$} \\
\hline & $\mathrm{AZ}$ & BBR & JBR & LBR \\
\hline \multicolumn{5}{|l|}{$0.95 \mathrm{a}_{\mathrm{w}}$-history culture: } \\
\hline $0.90 \mathrm{a}_{\mathrm{w}}$ & $3.03 \pm 0.4^{\mathrm{a}}$ & $2.44 \pm 0.3^{\mathrm{a}}$ & $3.06 \pm 0.3^{\mathrm{a}}$ & $3.10 \pm 0.4^{\mathrm{a}}$ \\
\hline $0.996 \mathrm{a}_{\mathrm{w}}$ & $2.97 \pm 0.3^{\mathrm{a}}$ & $2.55 \pm 0.2^{\mathrm{a}}$ & $2.18 \pm 0.4^{\mathrm{b}}$ & $2.97 \pm 0.2^{\mathrm{a}}$ \\
\hline $0.90 \mathrm{a}_{\mathrm{w}} \rightarrow 0.996 \mathrm{a}_{\mathrm{w}} \rightarrow 0.90 \mathrm{a}_{\mathrm{w}}$ & $3.21 \pm 0.3^{\mathrm{a}}$ & $2.51 \pm 0.3^{\mathrm{a}}$ & $2.94 \pm 0.2^{\mathrm{a}}$ & $3.07 \pm 0.5^{\mathrm{a}}$ \\
\hline $\begin{array}{l}0.996 \mathrm{a}_{\mathrm{w}} \rightarrow 0.90 \mathrm{a}_{\mathrm{w}} \rightarrow 0.996 \mathrm{a}_{\mathrm{w}} \\
0.996 \mathrm{a}_{\mathrm{w}} \text {-history culture }\end{array}$ & $2.72 \pm 0.4^{\mathrm{a}}$ & $2.39 \pm 0.3^{\mathrm{a}}$ & $2.27 \pm 0.4^{\mathrm{b}}$ & $3.14 \pm 0.5^{\mathrm{a}}$ \\
\hline $0.90 \mathrm{a}_{\mathrm{w}}$ & $2.96 \pm 0.4^{\mathrm{a}}$ & $2.48 \pm 0.3^{\mathrm{a}}$ & $3.10 \pm 0.2^{\mathrm{a}}$ & $2.89 \pm 0.3^{\mathrm{a}}$ \\
\hline $0.996 \mathrm{a}_{\mathrm{w}}$ & $2.83 \pm 0.5^{\mathrm{a}}$ & $2.58 \pm 0.5^{\mathrm{a}}$ & $2.13 \pm 0.4^{\mathrm{b}}$ & $3.09 \pm 0.5^{\mathrm{a}}$ \\
\hline $0.90 \mathrm{a}_{\mathrm{w}} \rightarrow 0.996 \mathrm{a}_{\mathrm{w}} \rightarrow 0.90 \mathrm{a}_{\mathrm{w}}$ & $2.69 \pm 0.3^{\mathrm{a}}$ & $2.41 \pm 0.2^{\mathrm{a}}$ & $3.04 \pm 0.4^{\mathrm{a}}$ & $2.97 \pm 0.2^{\mathrm{a}}$ \\
\hline $0.996 \mathrm{a}_{\mathrm{w}} \rightarrow 0.90 \mathrm{a}_{\mathrm{w}} \rightarrow 0.996 \mathrm{a}_{\mathrm{w}}$ & $3.11 \pm 0.2^{\mathrm{a}}$ & $2.60 \pm 0.3^{\mathrm{a}}$ & $2.21 \pm 0.5^{\mathrm{b}}$ & $2.89 \pm 0.3^{\mathrm{a}}$ \\
\hline
\end{tabular}

a, b Values followed by the same superscript letter within a column are not significantly different

occurs only if the preceding growth media is $0.996 \mathrm{a}_{\mathrm{w}}$.

\section{DISCUSSION}

This present study indicates that $A$. apis requires "wet" (water activity $\geq 0.90 \mathrm{a}_{\mathrm{w}}$ ) conditions for growth to occur, thus confirming observations by beekeepers that associate chalkbrood with high relative humidity in the colony. From our results, A. apis has these water-thermal characteristics: (1) growth increases with increasing temperature from 25 to $35{ }^{\circ} \mathrm{C}$, (2) optimal water activity for highest growth is $0.98 \mathrm{a}_{\mathrm{w}}$, (3) at 25 and $30{ }^{\circ} \mathrm{C}$ minimum water activity for cessation of growth is $0.85 \mathrm{a}_{\mathrm{w}}$, (4) at $35{ }^{\circ} \mathrm{C}$ minimum water activity for cessation of growth is $0.90 \mathrm{a}_{\mathrm{w}}$, and (5) water activities $\geq 0.95 \mathrm{a}_{\mathrm{w}}$ are required to produce spores. Attempts to make A. apis dry-suited (capable of using lower water activity), or wet-suited (capable of growing at higher water activity), using preconditioning treatments (Hadley 1994) were unsuccessful. Repeated subculturing on low or high water activity media, decreasing or increasing water activity, and cycling between different forms of hygric stress did not change waterthermal characteristics.

Water activity-temperature profiles are nearly superimposable for AZ and LBR and the $0.95 \mathrm{a}_{\mathrm{w}^{-}}$ history culture of JBR. The isolate BBR has a similar profile except the entire water activitytemperature relationship is shifted down the ordinate due to its slower growth. It is possible that the slower growth of BBR is biologically distinct for this isolate. It could be that the slow growth of $\mathrm{BBR}$ is related to low temperature injury from years of storage in a sub-zero freezer, and A. apis was recovered from tissue and not stored following cryopreservation techniques (Jensen et al. 2009). Another possibility is that BBR requires a more nutrient-rich medium, or $\mathrm{CO}_{2}$ in the incubator, than what was used in our experiments. Regardless of the cause of the slower growth, the information from BBR has value for understanding fungal water relations. Increased growth means increased water loss in fungi (Carlile et al. 2001), thus implying that BBR has lower water loss. The fact that water activities for growth were not lowered by lower water loss (i.e., slower growth) implies that the water activity of $A$. apis and water loss rate are independent characteristics.

Near pure water $\left(0.996 \mathrm{a}_{\mathrm{w}}\right)$ inhibited growth of JBR. Without $0.996 \mathrm{a}_{\mathrm{w}}$ pre-conditioning, JBR has a similar growth rate to $\mathrm{AZ}$ and LBR isolates. Thus, JBR can recover from the effects of high water activity pre-conditioning. Noteworthy was how quickly, usually $<1$ day, that JBR could switch from being a slow-grower to a fastgrower when it was transferred to any water activity $\leq 0.98 \mathrm{a}_{\mathrm{w}}$, and then how quickly it could 


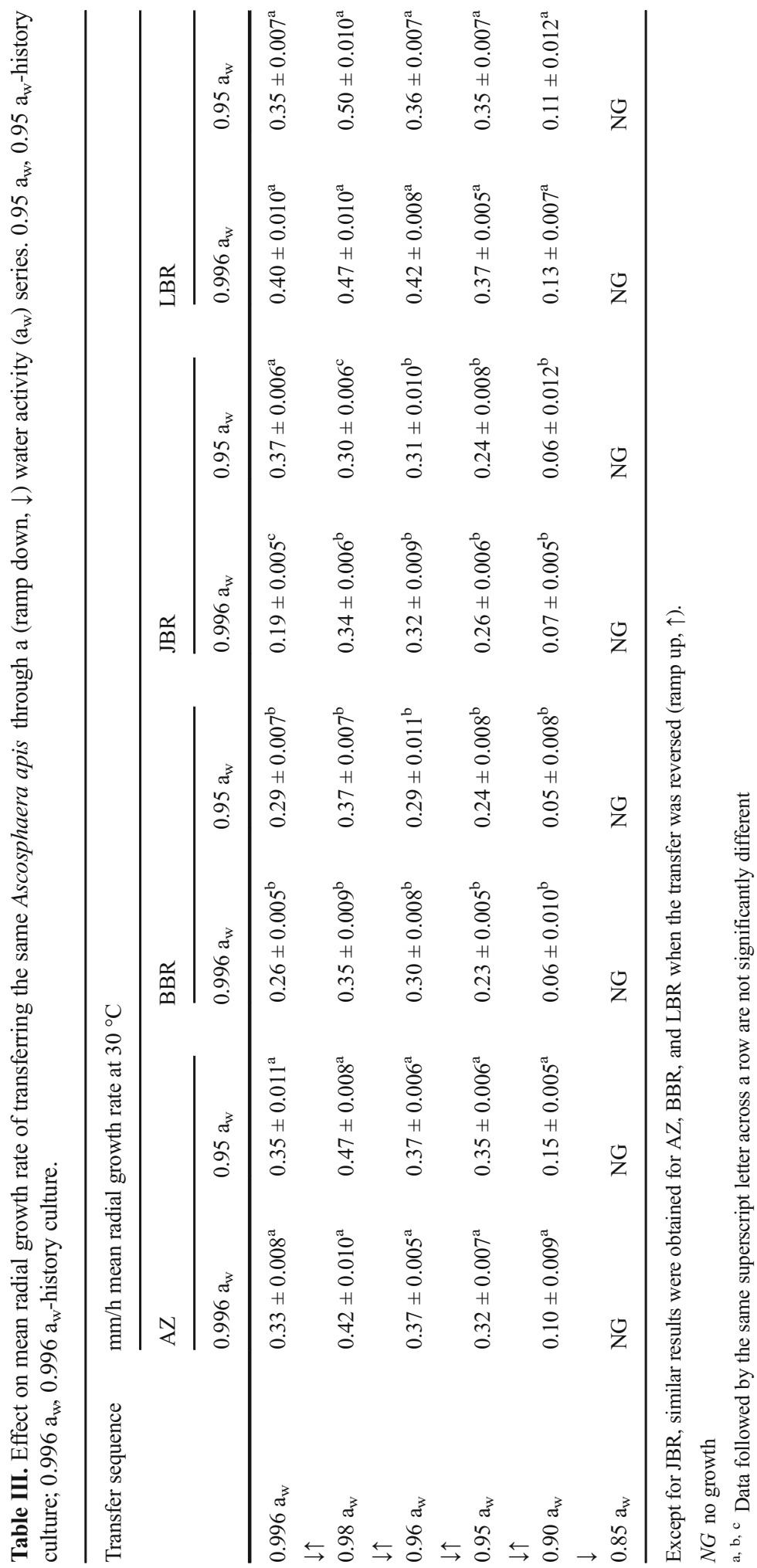


revert to a slow-grower when it was placed back on $0.996 \mathrm{a}_{\mathrm{w}}$. The sensitivity to overhydration by JBR is exemplified by its inability to grow at 0.95 and $0.96 \mathrm{a}_{\mathrm{w}}$ at $35{ }^{\circ} \mathrm{C}$, otherwise strong, growth-promoting conditions for other isolates. It is clear that JBR has problems handling overhydration stress. Whether JBR differs ecologically from AZ, LBR, and BBR is not known, as no data on its virulence, fitness, or differential life history characteristics are presently available. At this point, the only information that we have concerning JBR is that it is genetically distinct from LBR. This differential aspect of JBR is presently being investigated.

In fungi, increasing temperature increases water loss as a result of increase growth and metabolism (Carlile et al. 2001). It follows that water requirements of the fungus should be greater at higher temperatures to counter the increase water loss. This is precisely what occurs in A. apis; i.e., the $\mathrm{a}_{\mathrm{w}}$ at $35^{\circ} \mathrm{C}$ is higher than at 30 or $25^{\circ} \mathrm{C}$. The fact that water activity is higher still further for $0.996 \mathrm{a}_{\mathrm{w}}$-conditioned JBR implies either that the growth rates are particularly high (unlikely because $K_{\mathrm{r}}$ is suppressed); changes in cellular $\mathrm{a}_{\mathrm{w}}$ by uptake or secretion of solutes into the surrounding media to maintain water balance are not occurring; or the mechanism for restricting water loss by strengthening the cell wall is not operating (Carlile et al. 2001). In $0.996 \mathrm{a}_{\mathrm{w}}$-history culture of JBR, the water loss increase at $35^{\circ} \mathrm{C}$ must be so large that hyphal cells do not come into equilibrium with cellular water content to permit growth until the water activity of the growth medium is $0.98 \mathrm{a}_{\mathrm{w}}$, a moisture level at the maximum water activity and almost at saturation. JBR featured slower growth rates at all temperatures as a result of high water activity pre-conditioning that was not noted for the other isolates. An explanation for this reduced growth rate is that high water activity pre-conditioning makes JBR more temperature sensitive, which is a common cooccurring characteristic of a fungus that has a higher water activity (Grant et al. 1989). Indeed, the JBR isolate of $A$. apis has a higher water activity. This argues that the genetic difference between LBR and JBR includes greater temperature sensitivity for JBR.
Our results have direct application to the bee colony environment. The periphery of the colony is influenced more by fluctuating, ambient conditions outside the colony (Ellis 2008), which has implications for the rate of spore production and increased incidence of the disease (Gilliam et al. 1988; Flores et al. 1996). High relative humidity within the bee colony has the potential to moisten surfaces that permit $A$. apis growth (modified from Carlile et al. 2001). Dampness of $87 \%$ RH, $30{ }^{\circ} \mathrm{C}$ (Flores et al. 1996) and $>80 \% \mathrm{RH}$ (Liang et al. 2000) are sufficient for moistening surfaces to permit sexual reproduction of $A$. apis on chalkbrood mummies. Such a high level of moisture corresponds to A. apis' water activity $>0.90 \mathrm{a}_{\mathrm{w}}$.

Interior of the colony, between frames, and the brood nest are kept at $60-70 \% \mathrm{RH}$ and $35^{\circ} \mathrm{C}$ more or less year-round by healthy bees. The central brood area can get as low as $40-60 \% \mathrm{RH}$ between brood combs and 75-80\% RH inside a capped brood cell (Ellis 2008). Progressing outward from the central brood area of $35{ }^{\circ} \mathrm{C}$, the temperature drops to $25-30{ }^{\circ} \mathrm{C}$ at edges of the colony around the frames (Ellis 2008) where bee activity is not as great, less ventilated, and surfaces are closer to the surrounding environment. These cooler, damp conditions at the edge of colony are where chalkbrood mummies are found more frequently, corresponding to the water requirements for A. apis growth. The interior of the colony environment is a low water activity and high temperature niche that is suboptimal for chalkbrood development (Meikle and Holst 2015; Meikle et al. 2016).

Regions at the edge of the colony are less dried by ventilation activity by the bees. At the interior of the colony where conditions are dry denotes an internal restrictive microcosm to A. apis growth and where chalkbrood mummies are found less frequently. The high water activity requirement for A. apis implies that within the colony environment there is a greater likelihood of secondary spore production at the periphery of the colony. Such secondary spore production could impact infection rates and spore production on mummies leading to additional infections. Important information for beekeepers is that hot and dry conditions are especially limiting conditions for 
chalkbrood, and this can be controlled naturally by maintaining healthy bees for proper colony ventilation.

\section{ACKNOWLEDGMENTS}

Special thanks to Antonio J. Ramos (Applied Mycology Unit, Food Technology Department, University of Lleida, Lleida, Spain) for providing important literature on fungus water relations, and to Deanna Colby (USDA-ARS, Baton Rouge, LA) for critical evaluation and suggestions on the manuscript. We thank Dr. Michael A. Senich (Midland, TX) for funding.

Activité hydrique du champignon pathogène d'abeille Ascosphaera apis en relation avec les conditions de la colonie

couvain plâtré / colonie d'abeilles / humidité relative / microcosme / balance hydrique

Wasseraktivität eines Bienenpilzpathogens Ascosphaera apis in Relation zum Koloniezustand

Kalkbrut / Bienenkologie / Mykose / relative Feuchtigkeit / Wasserbalance / Mikrokosmos

\section{REFERENCES}

Aronstein, K.A., Cabanillas, H.E. (2012) Chalkbrood reexamined. In: Sammataro, D., Yoder, J.A. (eds.) Honey bee colony health: challenges and sustainable solutions, pp. 121-130. CRC Press, Boca Raton

Baldrian, P., Gabriel, J. (2002) Intraspecific variability in growth response to cadmium of the wood-rotting fungus Piptoporus betulinus . Mycologia 94, 428-436

Carlile, M.J., Watkinson, S.C., Gooday, G.W. (2001) The fungi. Academic, New York

Christensen, M., Gilliam, M. (1983) Notes on the Ascosphaera species inciting chalkbrood in honey bees. Apidologie 14, 291-297

Ellis, M.B. (2008) Homeostatsis: humidity and water relations in honeybee colonies (Apis mellifera). Magister
Scientiae. Department of Zoology and Entomology, University of Pretoria, Pretoria, South Africa

Evison, S.E.F. (2015) Chalkbrood: epidemiological perspective from the host-parasite relationship. Curr. Opin. Insect Sci.:doi 10.1016/j.cois.2015.04.015

Flores, J.M., Ruiz, J.A., Ruz, J.M., Puert, F., Bustos, M., Padilla, F., Campano, F. (1996) Effect of temperature and humidity of sealed brood on chalkbrood development under controlled conditions. Apidologie 27, 185-192

Gilliam, M., Taber III, S., Lorenz, B.J, Prest, D.B. (1988) Factors affecting development of chalkbrood disease in colonies of honey bees, Apis mellifera, fed pollen contaminated with Ascosphaera apis. J. Invertebr. Pathol. 52, 314-325

Grant, C., Hunter, C.A., Flannigan, B., Bravery, A.F. (1989) The moisture requirements of moulds isolated from domestic dwellings. Int. Biodeterior. Biodegrad. 25, 259-284

Hadley, N.F. (1994) Water relations of terrestrial arthropods. Academic, New York

Jensen, A.B., James, R.R., Eilenberg, J. (2009) Long-term storage of Ascosphaera aggregata and Ascosphaera apis, pathogens of the leafcutting bee (Megachile rotundata) and the honey bee (Apis mellifera). J. Invertebr. Pathol. 101, 157-160

Koenig, J.P., Mallory Boush, G., Erickson, E.H. Jr. (1987) Effects of spore introduction and ratio of adult bees to brood on chalkbrood disease in honeybee colonies. J. Apic. Res. 26, 191-195

Liang, Q., Chen, D., Wang, J. (2000) Effects of temperature, relative humidity and $\mathrm{pH}$ on germination of chalkbrood fungus, Ascosphaera apis spore. Ying Yong Sheng Tai Xue Bao 11, 869-872

Liu, G., Li, Y., Alva, A.K. (2012) Water potential vs. pressure in relation to water movement and transpiration in plants. Int. J. Agron. Plant Prod. 3, 369-373

Meikle, W.G., Holst, N. (2015) Application of continuous monitoring of honeybee colonies. Apidologie 46, 1022

Meikle, W.G., Weiss, M., Stilwell, A.R. (2016) Monitoring colony phenology using within-day variability in continuous weight and temperature of honey bee hives. Apidologie 47, 1-14

Rousseau, S., Donèche, B. (2001) Effect of water activity $\left(a_{w}\right)$ on the growth of some epiphytic micro-organisms isolated from grape berry. Vitis 40, 75-78

Sokal, R.R., Rohlf, F.J. (1995) Biometry: the principles and practice of statistics in biological research. Freeman, San Francisco 